\title{
1. Introduction: Historical transformation challenges established structures
}

\section{Risto Heiskala and Timo J. Hämäläinen}

The world economy is going through a historical transformation (Freeman and Perez, 1988; Freeman and Louca, 2001; Perez, 2002). This transformation has been labeled in various ways such as the 'rise of information society', 'globalization', the 'end of organized capitalism' and the 'rise of network society' (Bell, 1980; Lash and Urry, 1987; Held et al., 1999; Castells, 2000). However, even such broad definitions tend to describe only one dimension of the current systemic transformation which involves inter alia: (1) the rapid development and diffusion of information and communications technologies, (2) the globalization of economic activities through international trade, foreign direct investments and cross-border alliances, (3) the increasing specialization, complexity and knowledge-intensity of production processes, (4) the growing differentiation of demand patterns in consumer and producer markets, and (5) the spread of cooperative network arrangements in economic organization (Hämäläinen, 2003; Hämäläinen and Heiskala, 2004).

The historical paradigm shift has created a major structural adjustment challenge for the industrialized societies. The old socio-economic structures inherited from the postwar decades do not anymore perform very well in the radically changed technological and economic environment. Structural unemployment remains high in many industrialized countries, income and regional differences are rising and economic growth is slowed down by rigid economic and social institutions.

Many countries have responded to the paradigm shift in the world economy by increasing their investments in research and development, education and new infrastructures. However, as important as these policy measures are, they will not be sufficient for securing good economic performance in the coming decades. During historical transformation, socioeconomic systems need more comprehensive and systemic innovations and structural renewal. Otherwise the contradictions between the rapidly 
changing techno-economic subsystem and the slowly adjusting socioinstitutional subsystem of the society will grow too large. A growing mismatch between these two key parts of the society would increasingly hurt economic performance and social welfare (Freeman and Perez, 1988; Hämäläinen, 2003).

Unfortunately, the established innovation research has left policy makers pretty much on their own in responding to the major structural adjustment challenges of the current paradigm shift. Unlike the well-developed literature on technological innovations, research on social innovation processes is both scarce and scattered among various academic disciplines (Hämäläinen and Heiskala, 2004; Young Foundation, 2006). This book will provide fresh theoretical, empirical and policy-related insights into the social innovation and structural adjustment processes of modern societies, regions and industrial sectors. Only a deep understanding of such processes will help policy makers to develop effective policies to facilitate systemic adjustment.

Social innovations are often called for when rapid techno-economic change creates new social problems that cannot be fixed with old policy instruments (such as structural unemployment or increasing social and regional disparities). Such calls tend to be motivated by equity considerations. This book will argue that social innovations are also needed for good economic performance during major structural transformations. Societies, regions, industrial sectors and even firms are interdependent systems where narrowly focused or partial innovation only produces growing contradictions, poor productivity, decreasing returns and stagnating incomes. Social innovations in organizations, policies, rules and regulations, as well as in collective norms, values and cognitive frames, are needed to complement the more traditional technological and economic innovations in order to reach systemic synergies, rapid productivity growth, increasing returns and steadily growing incomes.

We believe that it is possible to develop a general theory of social innovation which could be applied at various analytical levels because, at their core, all social innovations involve collective learning processes of human communities. Such communities may consist of the citizens of a particular nation or region, employees and managers of an industrial sector, or members of an organization. As a result, we have included various case studies in this book that examine social innovation and structural change processes at different analytical levels: industrial sector, region and the society. Despite their different theoretical approaches and institutional contexts, the empirical similarities between our case studies suggest that the possibility of a general theory should be taken seriously in social sciences. Such a theory would be a real breakthrough in social sciences as well as private and public policy making. 
The book has two parts that complement each other. The first part sets the current techno-economic transformation into a longer-term historical perspective and argues that social innovations and (systemic) structural adjustment capacity are crucial for good economic performance during a major paradigm shift in the world economy. Chapters 2 and 3 provide two complementary theoretical frames with which one can analyze social innovation and structural change processes. The explanatory power of these theoretical lenses is demonstrated with a case study on Finnish society, which went through a major structural transformation in the 1980s and 1990s. The first part of the book ends with a chapter that discusses the different ways in which policy makers could facilitate social innovation and structural adjustment processes in their societies.

The second part of the book includes four other case studies from different analytical levels (sector, region, society) and geographical contexts (United States, Baden-Württemberg, Sweden and Ireland). These chapters provide additional theoretical, empirical and policy perspectives to the structural adjustment processes in the current paradigm shift. Taken together, the theoretical analyses and five case studies contained in this book provide new understanding of the dynamic and complex change processes in modern economies and the policy areas and tools with which decision makers may attempt to shape them.

Part I opens with two theoretical chapters. In Chapter 2, Timo Hämäläinen criticizes the established economic and social theories for being too narrow and static to fully grasp the nature of the current paradigm shift in the world economy. He then sets the current transformation into a historical perspective by presenting his theory of long socio-economic waves. Such waves have characterized the world economy since the first industrial revolution. According to Hämäläinen, we have now left behind the postwar catching-up phase in the world economy and entered into a new development phase where the most rapidly and comprehensively adjusting societies are likely to leave others behind in economic performance. He then lays out a theory of social innovation processes that emphasizes the importance of collective learning and various types of rigidities in structural adjustment processes.

Social innovations are not smooth and conflict-free processes that benefit all stakeholders equally. In Chapter 3, Risto Heiskala analyzes social innovations from structural and power perspectives. He begins by defining social innovations as those changes in regulations, social norms and shared mental frames that lead to new social practices and improved economic or social performance. Technological, economic and social innovations relate to different levels of the multi-layered typology of social structures that he introduces in the chapter. Heiskala points out that social innovations not 
only improve the collective resources of communities but may also lead to their redistribution among different stakeholders. In the latter case, social innovations produce a change in the hegemonic power balance.

In Chapter 4, the collective learning and hegemonic power perspectives of Hämäläinen (Chapter 2) and Heiskala (Chapter 3), respectively, are applied to the case of Finland's structural transformation in the 1980s and 1990s. Finland went through a major structural crisis and renewal process in the 1990s that fundamentally changed the Finnish economy and society. The structural transformation catapulted Finland to the top of the international competitiveness rankings and supported strong economic growth in the late 1990s and early 2000s. At the same time, however, some social groups and regions have been unable to adjust to the rapid change and have become marginalized.

Heiskala and Hämäläinen argue that Finland's rapid and successful structural change was facilitated by an alternative 'mental paradigm' that emerged in the margins of Finnish society in the 1980s to question the established postwar worldview, values, norms and strategies of Finnish society. The new mental paradigm was quickly adopted as the basis for decision making in the early 1990s once the old hegemonic paradigm was discredited by the deep crisis of the economy. The authors argue that collective learning (and unlearning) processes played a central role in the Finnish transformation. However, their case is also a good example of a hegemonic power shift from a hierarchically planned and culturally closed society towards a more open, market-oriented and technology-intensive one.

In Chapter 5, Hämäläinen draws the policy conclusions from his analysis of social innovation processes. He identifies several traditional policy areas (research, media and communications, education, culture, social security) where 'progressive' (unorthodox, future-oriented) policies can facilitate systemic change and structural adjustment processes. However, he also notes that policies in these areas often tend to be rather conservative and support the status quo. Hämäläinen also suggests new policy areas where active intervention can support structural change and renewal. These include: strategic policy intelligence activities (foresight, assessment, benchmarking), experimental pilot projects, facilitation of new inter-personal and inter-organizational networks, shared visioning and strategy processes among interdependent stakeholders and the development of reflective organizational cultures.

In Chapter 6, J.-C. Spender studies the evolution of the American auto industry and its relations with the government. Although he sides with the power-oriented explanations of institutional change presented by Heiskala (Chapter 3), Spender's case study also supports the ideas of Hämäläinen (Chapter 2) on the importance of the established mental 
paradigm ('industry recipe') in structural change processes. In particular, he traces the inability of the US auto industry to meet the challenges of increased competition by Japanese firms and tightening environmental regulations to the incapability of US car manufacturers to radically change their established 'industry recipe' - the industry leaders' shared mental paradigm. The historical power of the Big Three in the domestic markets and politics made them ill equipped for the new global competition of the auto industry. Spender claims that the changed economic environment calls for a profound analysis and transformation of the US auto industry's business recipe but he is not very optimistic that it will take place.

The following two chapters analyze structural change processes at the regional level in Baden-Württemberg, Germany, and in the Lake Mälar region, Sweden. However, these regions are also good examples of the national 'business systems' in these two countries. In Chapter 7, Gerd Schienstock introduces a theory of socio-economic development that distinguishes between evolutionary phases of 'path-dependence' and revolutionary phases of 'path creation'. His theory has many similarities with the theory of social innovation presented in Chapter 2. Schienstock applies his theory to explain Baden-Württemberg's economic success during the postwar decades ('path-dependence') and its subsequent economic decline in the 1980s and 1990s once it could not sufficiently renew its socio-economic structures (lack of 'path creation') in the face of growing international competition. The systemic benefits and historical success of the old business system became a structural burden once the more rapidly changing environment demanded more radical and comprehensive changes. Whether the recent attempts by local policy makers to 'create paths' in new industries yield long-term success remains to be seen. The inability of the regional government to provide a guiding vision for the region's transformation makes Schienstock pessimistic.

In Chapter 8 Gunnar Eliasson studies the Lake Mälar region, the industrial heartland of Sweden, that includes the cities of Stockholm, Södertälje, Uppsala and Västerås and has strong presence in three important industrial clusters (ITC, biotech and engineering), or 'competence blocs' as Eliasson prefers to call them. This is another example of an industrially successful and affluent region whose business system has met increasing problems in the present transformation of the world economy. According to Eliasson, the institutions and policies of the Swedish business system have been tailored to the needs of large manufacturing firms, while a successful transformation of the Läke Mälar regional economy would require the establishment of new knowledge-intensive firms which could absorb and utilize the sophisticated technologies and human capital that are being released from the troubled large firms. His 'competence bloc' analysis 
suggests that the region lacks the necessary receiver competencies, particularly sophisticated venture capital, that could prevent the released assets from flowing out of the country. Moreover, if such competencies could be built the increased locational attractiveness of the Läke Mälar region for sophisticated human capital and investments would increase the regional disparities within Sweden. As a result, he concludes that Sweden needs to attract more foreign investments and human capital in order to strengthen the local competence blocs.

Eliasson's competence bloc analysis is consistent with the argument for the importance of the systemic adjustment capacity in the current transformation (Chapter 2). It emphasizes the fact that advantages in one or two dimensions (for example, research and technology) are not enough to guarantee economic success in times of major structural transformation. $\mathrm{He}$ also underlines the mental rigidities of the Swedish public policy makers as the key problem in the development of a new institutional and policy framework that would be more supportive of industrial renewal. Long success creates mental rigidities that may require a deep crisis if they are to be overcome.

In the final chapter of the book, Julia O'Connor analyzes the remarkable success story of Ireland. This story is quite similar to that of Heiskala and Hämäläinen about Finland (Chapter 4). An economic and social crisis in the 1970s and 1980s led to a collective reframing process which produced a new, widely shared consensus that Ireland needed to change towards a more open and competitive society. An important feature of the Irish model is the broad-based policy dialogues through which the successful and widely shared policy visions are developed. They have involved all important social partners: the government, employers, labor unions, farmers and, more recently, the community and voluntary sector. The benefits of such a broad-based policy dialogue and widely shared vision in structural change processes were also underlined in Chapter 5.

O'Connor notes that the Irish government played an active role in building the competitiveness of the Irish economy but maintained a liberal welfare state with relatively low social expenditures despite the economy's openness. Such a growth- and competitiveness-oriented government role seems to promote growth also in other industrialized countries in the new economic environment (see Table 2.5). The old 'Big Tradeoff' between the equity- and efficiency-oriented goals of government policies has become more real in the global economy (Okun, 1975).

Finally, we would like to thank Edita Publishing Oy for allowing us to use some material in this book that they have earlier published in Finnish. 


\section{REFERENCES}

Bell, Daniel (1980), 'The social framework of the information society', in T. Forrester (ed.), The Microelectronics Revolution, Oxford: Blackwell.

Castells, Manuel (2000), The Information Age: Economy, Society and Culture, vol. I. The Rise of the Network Society, 2nd edition, Oxford: Blackwell.

Freeman, Chris and Francisco Louca (2001), As Times Go By: From the Industrial Revolutions to the Information Revolution, Oxford: Oxford University Press.

Freeman, Christopher and Carlota Perez (1988), 'Structural crises and adjustment, business cycles and investment behaviour', in Giovanni Dosi, Christopher Freeman, Richard Nelson, G. Silverberg and Luc Soete (eds), Technical Change and Economic Theory, London: Pinter Publishers.

Hämäläinen, Timo J. (2003), National Competitiveness and Economic Growth: The Changing Determinants of Economic Performance in the World Economy, Cheltenham, UK and Northampton, MA, USA: Edward Elgar.

Hämäläinen, Timo J. and Risto Heiskala (2004), Sosiaaliset innovaatiot ja yhteiskunnan uudistumiskyky, Helsinki: Edita.

Held, David, Anthony McGrew, David Goldblatt and Jonathan Perrathon (1999), Global Transformations: Politics, Economics and Culture, Cambridge: Polity.

Lash, Scott and John Urry (1987), End of Organized Capitalism, Oxford: Blackwell.

Okun, Arthur M. (1975), Equality and Efficiency: The Big Tradeoff, Washington, DC: Brookings Institution.

Perez, Carlota (2002), Technological Revolutions and Financial Capital: The Dynamics of Bubbles and Golden Ages, Cheltenham, UK and Northampton, MA, USA: Edward Elgar.

Young Foundation (2006), Social Silicon Valleys: A Manifesto for Social Innovation, What It Is, Why It Matters, How It Can Be Accelerated, London: Young Foundation. 
Risto Heiskala and Timo J. Hämäläinen - 9781847206992 Downloaded from PubFactory at 04/26/2023 10:58:02AM 